\title{
Respiratory Viral Infections in Pediatric Solid Organ and Hematopoietic Stem Cell Transplantation
}

\author{
Defne Arslan • Lara Danziger-Isakov
}

Published online: 12 September 2012

(C) Springer Science+Business Media, LLC 2012

\begin{abstract}
Respiratory viruses are common in children, including pediatric recipients of both solid organ transplantation and hematopoietic stem cell transplantation. The prevalence and risk factors in each of these groups are reviewed. Furthermore, associated morbidity and mortality in pediatric transplant recipients with respiratory viral infections are addressed. The literature on specific prevention and treatment options for respiratory syncytial virus, adenovirus, influenza, and other respiratory viruses in pediatric solid organ and hematopoietic stem cell transplant recipients is reported.
\end{abstract}

Keywords Respiratory virus $\cdot$ Pediatric $\cdot$ Pediatric solid organ transplant $\cdot$ Pediatric hematopoietic stem cell transplant $\cdot$ Respiratory syncytial virus $\cdot$ Influenza

\section{Introduction}

Respiratory viral infections (RVIs) in children can be caused by respiratory syncytial virus (RSV), adenovirus, rhinovirus, influenza virus, parainfluenza virus, human metapneumovirus (hMPV), and the emerging human coronaviruses and human bocaviruses. Although infection with these

\section{Arslan}

Case Western Reserve University, 10900 Euclid Avenue,

Cleveland, OH 44106, USA

e-mail: dea18@case.edu

L. Danziger-Isakov $(\bowtie)$

Pediatric Infectious Diseases, Cincinnati Children's Hospital

Medical Center,

MLC 7017, 3333 Burnet Avenue,

Cincinnati, OH 45229-3039, USA

e-mail: Lara.Danziger-Isakov@cchmc.org pathogens often results in a mild, self-limiting illness, complications can arise. Immunocompromised children may experience significant morbidity and mortality related to RVIs, as compared with their otherwise healthy counterparts. We review the current literature regarding RVIs in immunocompromised children-specifically, recipients of hematopoietic stem cell transplantation (HSCT) or solid organ transplantation (SOT) - in order to appreciate the significance of these pathogens and to discuss the methods available to reduce RVI-associated morbidity and mortality in pediatric transplant recipients.

\section{Epidemiology}

RVIs in Immunocompetent Children

Respiratory illness is the leading cause of hospitalization in children with an incidence of approximately $30 \%$ [1]. Furthermore, at least $40 \%$ of these admissions are secondary to RVI [2]. In children presenting to the hospital with acute respiratory tract symptoms, antigen detection, viral culture, or PCR will identify a viral pathogen in as many as $87 \%$ of episodes [3]. The most common viruses recovered include RSV, rhinovirus, adenovirus, influenza virus, parainfluenza virus, enterovirus, and hMPV. In over $25 \%$ of events, multiple viruses have been isolated simultaneously [3]. Discovered in 2001, hMPV has been isolated in as many as $20 \%$ of childhood lower respiratory tract infections [4]. Furthermore, influenza virus alone has been estimated to affect 90 million children under the age of 4 in a single year, with 20 million calculated to progress to lower respiratory tract infection [5]. Studies of RSV have estimated that 2 million children with RSV require medical attention each 
year, with increased risk for hospitalization in premature infants and younger children [6]. In summary, RVIs occur frequently and have a substantial impact on child health even in immunocompetent populations.

\section{RVIs in Pediatric Solid Organ Transplant Patients}

While RVIs have been commonly recognized in pediatric SOT recipients for decades, longitudinal prospective surveillance data in this population are currently lacking, particularly in nonlung SOT populations. Retrospective studies suggest that RVIs are the most common infectious episodes after pediatric kidney and liver transplantation, with 2.7 episodes per patient-year [7]. Overall, rhinovirus is reported as the most common respiratory viral pathogen in pediatric SOT recipients, with a seasonal peak in the spring and fall months similar to community patterns (Table 1 ). The largest reported experience is from the pediatric lung transplant population, where $13 \%-51 \%$ of children experienced an RVI in the first few months following transplantation [8-10•]. The viruses isolated in this study were similar to those in immunocompetent individuals and included adenovirus, rhinovirus, RSV, and parainfluenza virus [9, 10•]. These viruses were more likely to progress to lower respiratory tract infections (LRTIs), rather than remain limited to the upper respiratory tract (URTIs), in this cohort [9]. Younger patients and those receiving double lung transplants were at increased risk for RVI [10•]. Further prospective investigation to assess the incidence and risk factors for RVI in pediatric SOT is needed, especially outside of the pediatric lung transplant population.

\section{Complications of RVI in SOT}

Although the rates of RVIs in transplant patients were comparable to those in their otherwise healthy peers $[7,11]$, the risk for RVI-associated complications may be more significant. For example, a 9-month-old liver transplant recipient developed severe respiratory failure with hMPV in the immediate posttransplant period [12]. Their and colleagues reported that up to $23 \%$ of RVIs in kidney and liver transplant recipients were complicated by bacterial superinfection, including acute otitis media and sinusitis, and $15 \%$ received multiple courses of antibiotics [7]. Furthermore, $18 \%$ underwent surgical intervention for recurrent otitis media, which outpaces the rates in nontransplant recipients. In lung transplant recipients, where RVI directly affects the graft, complications are frequently reported. Most published studies to date have focused on adults, with acute decline in respiratory function or increased risk of acute rejection with RVI $[8,13]$. Chronic graft rejection, known as bronchiolitis obliterans syndrome (BOS), following RVI has been reported in several cohorts [13-15]. However, to date, RVI has not been found to be associated with increased incidence of acute rejection or BOS after pediatric lung transplantation $[9,10 \bullet]$.

Influenza has been particularly prominent in the literature since the 2009 H1N1 pandemic. For example, a 12-year-old boy who was 8 years post-cardiac-transplant developed H1N1 influenza during this outbreak, complicated by respiratory failure requiring extracorporal membrane oxygenation (ECMO) support for 24 days [16]. As compared with adults, pediatric patients had a lower incidence of ICU admission (12\% vs. $17 \%)$ and mechanical ventilation ( $4 \%$ vs. $12 \%$ ). Furthermore, there were no pediatric deaths in 83 cases, as compared with 10 in 154 adults (6\%) [17••]. Interestingly, the pediatric population was more likely than adults to receive antiviral medications within $48 \mathrm{~h}$ of symptom onset, which may have affected outcomes and may reflect bias toward early intervention for pediatric SOT recipients with RVI symptoms.

Parainfluenza, influenza, and adenovirus were reported to impact mortality in the older pediatric literature; however, reports of mortality secondary to RVI have decreased in the recent transplant era. From 1987 to 1992, mortality from influenza and parainfluenza was $23 \%$ and $15 \%$, respectively, in a single-center series from Pittsburgh [18]. Similarly, 2 of 16 pediatric lung transplant recipients who developed adenovirus expired secondary to their infection from 1994 to 1996 in Philadelphia [19]. However, more recent literature shows overall good prognosis in RVI after pediatric SOT. In liver, kidney, and lung transplant recipients, overall mortality has decreased significantly $[7,10$, 20]. Further studies focusing on the impact of RVIs in pediatric SOT recipients, including changing patterns of morbidity and mortality, would benefit this population.

\section{RVIs in Pediatric Hematopoietic Stem Cell Transplant} Patients

Similar to pediatric SOT, pediatric recipients of HSCT experience RVIs in the posttransplant period. Rhinovirus is again among the most common pathogen recovered, infecting $20 \%$ of some cohorts (Table 1). Acquisition of these viral infections occurs at equal frequencies among patients at various phases of immunologic recovery following transplant (neutropenic phase, early engraftment phase, and late engraftment phase) [21]. A significant proportion of HSCT patients who test positive for a single respiratory virus also test positive for other copathogens (viruses, bacteria, and fungi), further complicating treatment strategies [21-23].

Data suggest that URTIs are equally or more likely than LRTIs in HSCT children [21, 24]. Unlike SOT, where age and type of organ transplanted affect risk of RIV, age and source of transplanted cells (bone marrow, peripheral blood, or cord blood) do not appear to impact the development of 
Table 1 Frequencies and Seasonality of RVIs in Pediatric Transplantation

\begin{tabular}{llll}
\hline Respiratory virus & Frequency (\%) & Seasonal peaks & Population \\
\hline Solid organ transplantation & & & \\
Rhinovirus [9, 10•] & $3-15$ & Spring, Fall & Pediatric \\
Influenza [8, 10•] & $1-3$ & Spring, Winter & Pediatric \\
Respiratory syncytial virus [10•, 47] & $3-11$ & Spring, Fall, Winter & Pediatric \\
Adenovirus [10•] & 3 & Spring & Pediatric \\
Parainfluenza virus [10•, 18] & $3-6$ & Summer & Pediatric \\
Hematopoetic stem cell transplant & & & \\
Rhinovirus [23] & $19-21$ & Fall & Pediatric and adult \\
Influenza [21, 28] & $2-5$ & Spring, Fall & Pediatric \\
Respiratory syncytial virus [21, 22•, 94] & $2-10$ & Winter & Pediatric and adult \\
Adenovirus [21] & 2 & Fall & Pediatric \\
Parainfluenza virus [21, 22•] & $4-5$ & Summer & Pediatric and adult \\
Coronavirus [23] & 10 & Winter and Spring & Pediatric and adult \\
Human metapneumovirus [94, 95] & $6-7$ & Winter and Spring & Pediatric and adult \\
\hline
\end{tabular}

RVIs in HSCT recipients [23]. Conversely, the type of transplant, autologous or allogeneic, may influence risk of RVI. Pediatric allogeneic HSCT was significantly associated with symptomatic parainfluenza viral infections, as compared with autologous HSCT [25]. It has been suggested that HLA compatibility and development of chronic GVHD may influence one's risk for developing a viral infection after HSCT, although data are limited and only $9 \%$ of the infections in the reported cohort were RVI [26].

\section{Complications of RVIs in HSCT}

Complications of RVI in HSCT patients are similar to those in SOT recipients and include prolonged hospitalization, $\mathrm{BOS}$, chronic lung disease, ECMO, mechanical ventilation, GVHD, and death [25, 27, 28]. During the 2009 H1N1 influenza A pandemic, hospitalization occurred more frequently in HSCT patients with influenza $\mathrm{A}$ and severe neutropenia $(\mathrm{ANC}<500 \mathrm{~K} / \mathrm{uL}$ ) than in those with symptoms of RVI but normal neutrophil counts [28]. Although not routinely used for prognostic purposes, high viral loads in BAL samples have been found to be associated with subsequent mechanical ventilation in pediatric and adult HSCT recipients. The quantitative viral load in these BAL samples was not correlated with mortality; rather, presence of serum viral RNA put these patients at twofold increased risk for mechanical ventilation and death [22•]. Donor HLA mismatch, although potentially associated with initial infection, has not been linked with subsequent morbidity or mortality [25, 27]. Pretransplant conditioning, however, did impact clinical course following RVI; patients receiving total body irradiation experienced more complications than did those receiving a chemotherapy-based conditioning regimen [25, 27]. It appears that the complications of RVI in SOT and HSCT patients are quite similar; the risk of complication, however, may depend closely on the protocols associated with each transplant.

\section{Diagnosis}

Current diagnostic tools allow for identification of a viral etiology for an upper respiratory tract infection in almost $60 \%$ of cases collected from a nasal swab [29]. However, investigation of healthy infants within the first year of life demonstrated that viral isolation in asymptomatic children may also occur in nearly $25 \%$ of nasopharyngeal specimens [30]. Thus, identification of high-risk groups likely to benefit from specimen sampling will continue to be an essential endeavor as diagnostic tests become more sensitive and specific.

One study created a symptom grade model to identify patients more likely to benefit from sampling. The authors of this study created four separate models, each utilizing qualitative measures of common RVI symptoms (rhinorrhea, cough, fever, and others) along with a quantitative assessment of symptom duration to assign severity scores to pediatric patients. The most successful model in this study (utilizing significant runny nose for 1-4 days and significant cough for 1-4 days) demonstrated a positive predictive value and a negative predictive value of $75 \%$ and $70 \%$, respectively [29]. Furthermore, in younger children, where symptom quality and severity is less likely to be elicited, establishment of criteria was less useful. The utility of these models was not assessed in SOT or HSCT populations.

Investigations have moved toward optimizing testing protocols, since transplant patients are particularly susceptible to complications that arise from delayed or incomplete diagnosis. With the application of RT-PCR to identify viral 
etiologies in immunocompromised children [31], there has been a $15 \%-28 \%$ improvement in detection $[32,33]$, as well as a $36 \%$ expansion of viruses detected, as compared with conventional rapid viral culture and direct fluorescence antigen (viral culture/DFA) multiplex methods [33]. Additionally, PCR has been shown to detect viruses in samples with fewer viral copies than either of these conventional methods, as well as in patients with mild to absent respiratory symptoms [34•]. PCR has recently been incorporated into the International Society of Heart and Lung Transplant's (ISHLT) guidelines for diagnosing RVIs in cardiothoracic transplant recipients; it has become a wellestablished tool for identifying a viral etiology, a step that is required to officially diagnose URTI or LRTI per these standards [35].

Recently, multiplex platforms that can test simultaneously for multiple viruses on a single respiratory sample have been approved for commercial use. Two of these platforms, the FilmArray Respiratory Viral Panel (FA-RVP; Idaho Technology, Salt Lake City, UT) and the Luminex xTAG Respiratory Viral Panel (xTAG-RVP; Luminex, Austin, TX), have been compared with regard to sensitivity, specificity, utility, and cost. The xTAG-RVP is one of the first FDA approved multiplex assays and detects 12 viruses: RSV A and B, influenza A (H1, H3, and untypable), influenza B, parainfluenza 1, 2, and 3, human metapneumovirus, adenovirus, and enterovirus. FA-RVP was approved in 2011 and identifies human coronaviruses NL63 and HKU1 and parainfluenza 4 , in addition to those viruses identified by xTAG-RVP. A recent study looking at respiratory samples from pediatric cancer patients determined that the FA-RVP platform was better able to identify pathogens in nasopharyngeal samples than was the xTAG-RVP platform. Moreover, the FA-RVP protocol was faster than the xTAG-RVP protocol; however, xTAG-RVP was found to have a higher throughput and better reliability than FA-RVP [36]. The decision regarding the best platform will clearly depend on considerations for local populations, laboratory volumes, and the development of future platforms.

The ideal method of sampling has also come into question, since the yield of viral specimen may differ depending on the specimen source. A study investigating the quality of nasopharyngeal and oropharyngeal specimens in adults with RVIs demonstrated significant superiority of nasopharyngeal washes to both nasopharyngeal and oropharyngeal swabs [37]. However, when paired with nasopharyngeal swabs in children, oropharyngeal samples were able to increase the detection of respiratory viruses by $15 \%$ over detection with nasopharyngeal swab alone [38]. While samples from the lower airways are often considered to have a higher yield than those in the upper airways, lower respiratory tract samples (such as bronchoalveolar lavage) are acquired through invasive procedures and may not be available for all patients. One third of asymptomatic children tested positive for viral infection in a study examining bronchoalveolar lavage isolates, raising the question of whether all results from invasive testing are clinically significant [39]. Nevertheless, in patients who require lower respiratory tract investigation for alternative reasons, such as investigation of rejection episodes in lung transplant recipients or evaluation for bacterial or fungal pathogens, lower tract sampling may be warranted.

\section{Prevention Strategies}

The prevention of RVIs in pediatric transplant patients has been a critical tool for minimizing both infections and their associated complications. Vaccination and antiviral prophylaxis will be discussed within the context of specific viruses; however, prevention strategies focusing on environmental factors and health-care delivery systems have also been investigated to reduce the incidence of RVIs. These precautions have included cohorting patients, applying contact or respiratory droplet precautions, assigning specific healthcare staff to infected patients, and screening of visitors $[40,41]$. Each of these infection prevention strategies has been shown to significantly decrease the incidence of nosocomial RVIs in HSCT patients and has subsequently been incorporated into the Center for Disease Control and Prevention (CDC) Healthcare Infection Control Practices Advisory Committee's recommendations to reduce health-careassociated pneumonia [42]. Methods for reducing RVIs in HSCT patients are also specifically addressed in collaborative guidelines by the CDC, the Infectious Diseases Society of America, and the American Society for Blood and Marrow Transplantation published in 2001 [43].

\section{Virus-Specific Prevention and Treatment}

Respiratory Syncytial Virus

\section{Prevention}

The pediatric transplant community has recognized the importance of RVI prophylaxis in susceptible patients for diminishing associated morbidity and mortality [44]. In 1998, the FDA approved palivizumab, a humanized monoclonal antibody against the fusion protein of the RSV virus, for the prevention of severe RSV infection in high-risk pediatric patients. Since that time, several studies have demonstrated the efficacy of palivizumab in suppressing the acquisition and spread of RSV in immunocompromised subjects [40, 45, 46]. A 2009 study reported on current RSV prophylaxis strategies found that U.S. pediatric 
transplant centers offered RSV prophylaxis, mostly palivizumab (97\%), in $49 \%$ of candidates and recipients of SOT [47]. Palivizumab was most often given to children under the age of 2 years, consistent with 2009 recommendations from the American Academy of Pediatrics [48].

The true efficacy of palivizumab in preventing RVIassociated morbidity in transplant patients is still up for debate. One decision analysis model of outcomes in pediatric HSCT patients given palivizumab for RSV prophylaxis predicted a $10 \%$ increase in survival in patients offered immunoprophylaxis [49]. However, another analysis evaluated the use of palivizumab in preventing RSV progression to lower respiratory tract disease in 40 pediatric and adult allogeneic HSCT recipients and concluded that palivizumab did not impact RSV-associated morbidity or mortality [50]. Further investigation predicted a number needed to treat of $12-15$ for palivizumab in high-risk children $[49,51]$. Due to its high cost, some have expressed concern with offering palivizumab prophylaxis too widely. One study estimated that over $\$ 150,000$ would be required to prevent one patient admission secondary to RSV infection with palivizumab in the general pediatric population [51]. Therefore, risk assessment is now a common and appropriate step in determining the need for RSV prophylaxis in a particular pediatric patient and has been incorporated into the most current recommendations of the American Association of Pediatrics (AAP) for the use of palivizumab in RSV prevention [48].

\section{Treatment}

For the treatment of RSV, the most studied antiviral has been ribavirin, a synthetic nucleoside analog FDA approved for the treatment of severe RSV pneumonia in children. Early studies investigating ribavirin's ability to clear RSV infection in immunocompromised patients were promising; however, these patients were identified shortly after infection, most not yet having become symptomatic [52]. These data likely cannot be generalized, since most pediatric transplant centers do not routinely test asymptomatic patients for RVIs and intervention is delayed until symptoms arise. In fact, several subsequent studies have suggested that effective ribavirin treatment is time dependent, with progression to LRTI representing a significant indicator of poor prognosis $[53,54]$. In addition, alternative routes of delivery, including oral and intravenous ribavirin, have been investigated in adult lung transplant recipients, but these have not been reported in pediatric subjects to date [55-57]. Due to inconsistent results with ribavirin, especially in these children whose RSV infection extends into the lower respiratory tract, several studies have advocated for the concomitant use of immunoglobulin or palivizumab in high-risk children $[58,59]$; palivizumab was not shown to decrease the risk of mortality or progression to lower tract disease in at least one study of 40 patients [50]. Further investigation of novel treatment strategies is warranted.

\section{Adenovirus}

Although adenoviral infection remains a significant threat in the pediatric transplant population, no formally approved and few effective treatment options exist. Several antiviral and replacement therapies have been attempted, including ribavirin, ganciclovir, vidarabine, cidofovir, intravenous immunoglobulin, and leukocyte transfusions, without definitive success.

Ribavirin has long since been identified as effective at clearing several viral infections, including adenovirus, in vitro [60]. Clinical studies of the efficacy of ribavirin in adenovirus have been less convincing, with only minimal to mild improvement of adenoviral infection with intravenous or aerosolized in small-population clinical studies [61, 62].

Cidofovir, originally approved to treat cytomegalovirus in HIV patients, is a phosphonate nucleotide analog that inhibits viral DNA polymerase that has more recently been shown to have broad-spectrum antiviral activity against several DNA viruses, including adenovirus [63]. Several studies have investigated the utility of cidofovir in pediatric transplant recipients with adenovirus and have shown overall efficacy and safety in this population [64-66]. Yet with an unfavorable toxicity profile, cidofovir remains an imperfect treatment, with deaths reported secondary to disseminated adenoviral infection in treated patients [67]. In an effort to optimize outcomes using cidofovir, a metaanalysis investigating adenoviral disease in HSCT patients suggests categorizing patients by level of risk [68]. Using this method, a dose of $1 \mathrm{mg} / \mathrm{kg} /$ day or $5 \mathrm{mg} / \mathrm{kg} /$ week has been proposed until viral load drops below 400 copies per milliliter in at least two consecutive samples [68]. Case series in pediatric lung transplantation have additionally reported successful treatment of adenovirus infection with low-dose cidofovir ( $1 \mathrm{mg} / \mathrm{kg} /$ dose every other day) in conjunction with probenicid, hydration, and intravenous immunoglobulin [20].

\section{Influenza}

\section{Prevention}

Vaccination remains the public health sector's primary effort to prevent the acquisition and transmission of influenza. The seasonal influenza vaccine covers predicted widespread strains of both the influenza A and influenza B subtypes. During each influenza season, further antigenic characterization allows for specific strain identification and incorporation into the following year's preparation. Routes of administration for the seasonal influenza vaccine include 
intramuscular, intradermal, and intranasal. For the pediatric population, two preparations are available in the United States: the trivalent inactivated intramuscular vaccine (6 months of age and older) and the live attenuated intranasal vaccine ( 2 years of age and older). Live attenuated vaccination is not recommended in posttransplant recipients [69]; however, it may be used in close contacts of transplant recipients if inactived virus is not available.

Protection from influenza infection following vaccination occurs via antibody and cell-mediated immune responses. Although studies in pediatric transplant recipients have demonstrated a generally adequate antibody response to influenza vaccination in this population [70-72], cellmediated responses may be suboptimal [70]. This finding is likely related to immunosuppression regimens in transplant recipients, which aim to minimize T-cell-mediated graft dysfunction. Details of the immunosuppression and vaccination protocols have also been investigated in an attempt to further optimize vaccination responses. For instance, steroid-sparing agents do not appear to offer an advantage over steroid-containing agents in terms of the magnitude of the antibody response to influenza vaccination, as demonstrated in a study of pediatric kidney transplant recipients [71]. Furthermore, additional booster doses of the influenza vaccine have not been shown to increase serological conversion rates in pediatric kidney and liver transplant recipients [71-73]. Vaccination against influenza is strongly suggested for family members and close contacts (including health-care workers) of SOT and HSCT recipients to create a "circle of protection" around the immunocompromised host [74].

The 2009 pandemic H1N1 influenza vaccine has received particular attention. Vaccination against the H1N1 strain has been shown to offer protection in pediatric transplant recipients, without significant adverse effects [72, 75-77]. Serologic conversion rates may be lower following $\mathrm{H} 1 \mathrm{~N} 1$ vaccination in pediatric transplant recipients than in healthy controls; however, administration in coordination with the seasonal influenza vaccine allowed for bolstered immune responses in this population [78]. Contrary to seasonal influenza vaccine, an additional booster dose of the H1N1 vaccination was shown to increase seroconversion rates from $62 \%$ to $82.5 \%$ in a group of pediatric liver transplant recipients [79]. However, the 2011 AST guidelines did not recommend booster vaccination, since data were still limited [69].

Aside from vaccination, prevention of influenza has been suggested through the use of prophylactic antivirals. Oseltamivir, a potent neuraminidase inhibitor used to treat influenza, has been studied as a prophylactic agent in pediatric cancer patients [80]. No cases of influenza were noted in the population offered oseltamivir for prophylaxis, and few minor side effects were reported. A recent study compared oseltamivir prophylaxis with placebo in a cohort of mostly adult (96\%) SOT and HSCT recipients and reported a significant decrease in laboratory-confirmed influenza as determined by reverse transcriptase-PCR over the 12-week study period with oseltamivir prophylaxis (1.7\% vs. $8.4 \%$ in placebo) [81]. Oseltamivir resistance in the immunocompromised population has surfaced $[81,82]$, reminding clinicians that the choice of a prophylactic antiviral should be determined on the basis of the properties of the current circulating influenza virus. Amantadine, another antiviral that interferes with viral uncoating, has been utilized less, due to resistance noted during the 2008-2009 season [83]. Recommendations regarding appropriate prophylactic agents are revised and published yearly by the CDC, WHO, and collaborating laboratories based on current resistance patterns of circulating influenza strains.

\section{Treatment}

The pandemic novel influenza A/H1N1 strain in 2009 created a resurgence of literature evaluating antiviral treatment options for high-risk patients. The oral neuraminidase inhibitor oseltamivir is indicated for the treatment of uncomplicated influenza A or B infection in children 1 year and older who have been symptomatic for no more than $48 \mathrm{~h}$. Dosing ranges from 30 to $75 \mathrm{mg}$ twice a day based on weight. A primary goal in the treatment of influenza in transplant patients is to offer antiviral treatment as soon as possible after initial presentation. Oseltamivir has been shown to significantly reduce hospital stays in critically ill children infected with seasonal influenza [84], and SOT recipients with pandemic influenza $\mathrm{A} / \mathrm{H} 1 \mathrm{~N} 1$ demonstrated a $60 \%$ lower ICU admission rate in patients offered oseltamivir within $48 \mathrm{~h}$ of symptom onset $[17 \bullet \bullet]$.

Zanamivir is an inhaled neurominidase inhibitor that has been less frequently utilized but may offer an alternative treatment for those unresponsive to oseltamivir [85]. Its indications are similar to those of oseltamivir, except that it is recommended for children 7 years and older. Dosing is $10 \mathrm{mg}$ twice daily for 5 days, delivered via an oral inhalation disk. Peramivir is a neurominidase inhibitor that was granted emergency use authorization by the Federal Drug Association in 2009 for the treatment of influenza infection in hospitalized adult and pediatric patients requiring IV therapy following failure of oral and inhaled antiviral medications [86]. This was the first intravenous antiviral medication available for the treatment of influenza, although intravenous formulations of oseltamivir and zanamivir are under investigation (clinicaltrials.gov). Peramivir is licensed in Japan and South Korea and has been found to be effective against susceptible influenza $\mathrm{A}$ and $\mathrm{B}$ viruses. A phase 3 clinical trial is currently underway to examine the effect of adding peramivir to institutional standards of care in 
improving symptoms and nasopharyngeal viral loads in adults and adolescents hospitalized with influenza infection (clinicaltrials.gov). Preliminary studies conducted in Japan have demonstrated improvement in symptoms and reduction of viral loads in pediatric patients given $10 \mathrm{mg} / \mathrm{kg} / \mathrm{day}$ of peramivir infusion for influenza infection [87, 88]. Studies in transplant patients have not yet been reported. Despite the availability of several antiviral medications for the treatment of influenza, current management strategies focus on prevention of infection in susceptible hosts through vaccination, since complications arising from infection can be quite severe [89].

\section{Other Respiratory Viruses}

Treatment of other respiratory viruses, including parainfluenza virus and human metapneumovirus, has been reported in the literature; however, these are generally case reports and not randomized clinical trials to gauge the efficacy of antiviral intervention. Ribavirin has been reported as a potential strategy for treating both parainfluenza virus and human metapneumovirus in the context of case reports and series of adult SOT and pediatric HSCT recipients, although successful responses have not been consistent $[13,25$, 90-93]. However, supportive therapy without antivirals has also been successful in other reports, and further evaluation of potential treatment strategies for these common respiratory viral pathogens is warranted $[12,18,21]$.

\section{Conclusion}

Respiratory viral infections affect pediatric recipients of both SOT and HSCT. Prevalence appears similar to that for other children; however, increased risk of morbidity and mortality should influence care-givers to be vigilant about detecting RVIs in these children. Prevention is essential, including vaccination against influenza. Further investigation into treatment modalities is needed to expand treatment options.

Disclosure No potential conflicts of interest relevant to this article were reported.

\section{References}

Papers of particular interest, published recently, have been highlighted as:

- Of importance

•- Of major importance

1. U.S. Department of Health and Human Services HRaSA, Maternal and Child Health Bureau. Child Health USA 2010. Rockville, Maryland; 2010.
2. Henrickson KJ, Hoover S, Kehl KS, Hua W. National disease burden of respiratory viruses detected in children by polymerase chain reaction. Pediatr Infect Dis J. 2004;23(1 Suppl):S11-8.

3. Jennings LC, Anderson TP, Werno AM, Beynon KA, Murdoch DR. Viral etiology of acute respiratory tract infections in children presenting to hospital: role of polymerase chain reaction and demonstration of multiple infections. Pediatr Infect Dis J. 2004;23(11):1003-7.

4. Williams JV, Harris PA, Tollefson SJ, Halburnt-Rush LL, Pingsterhaus JM, Edwards KM, et al. Human metapneumovirus and lower respiratory tract disease in otherwise healthy infants and children. N Engl J Med. 2004;350(5):443-50.

5. Nair H, Brooks WA, Katz M, Roca A, Berkley JA, Madhi SA, et al. Global burden of respiratory infections due to seasonal influenza in young children: a systematic review and meta-analysis. Lancet. 2011;378(9807):1917-30.

6. Hall CB, Weinberg GA, Iwane MK, Blumkin AK, Edwards KM, Staat MA, et al. The burden of respiratory syncytial virus infection in young children. N Engl J Med. 2009;360(6):588-98.

7. Their M, Holmberg C, Lautenschlager I, Hockerstedt K, Jalanko $\mathrm{H}$. Infections in pediatric kidney and liver transplant patients after perioperative hospitalization. Transplantation. 2000;69(8):161723.

8. Soccal PM, Aubert JD, Bridevaux PO, Garbino J, Thomas Y, Rochat $\mathrm{T}$, et al. Upper and lower respiratory tract viral infections and acute graft rejection in lung transplant recipients. Clin Infect Dis. 2010;51(2):163-70.

9. Liu M, Mallory GB, Schecter MG, Worley S, Arrigain S, Robertson $\mathrm{J}$, et al. Long-term impact of respiratory viral infection after pediatric lung transplantation. Pediatr Transplant. 2010;14(3):431-6.

10. • Liu M, Worley S, Arrigain S, Aurora P, Ballmann M, Boyer D, et al. Respiratory viral infections within one year after pediatric lung transplant. Transpl Infect Dis. 2009;11(4):304-12. This article provides the most comprehensive epidemiology of respiratory viral infections after pediatric lung transplantation.

11. Gerna G, Piralla A, Rovida F, Rognoni V, Marchi A, Locatelli F, et al. Correlation of rhinovirus load in the respiratory tract and clinical symptoms in hospitalized immunocompetent and immunocompromised patients. J Med Virol. 2009;81(8):1498-507.

12. Evashuk KM, Forgie SE, Gilmour S, Huynh H, Lee BE, Robinson JL. Respiratory failure associated with human metapneumovirus infection in an infant posthepatic transplant. Am J Transplant. 2008;8(7):1567-9.

13. Hopkins P, McNeil K, Kermeen F, Musk M, McQueen E, Mackay I, et al. Human metapneumovirus in lung transplant recipients and comparison to respiratory syncytial virus. Am J Respir Crit Care Med. 2008;178(8):876-81.

14. Khalifah AP, Hachem RR, Chakinala MM, Schechtman KB, Patterson GA, Schuster DP, et al. Respiratory viral infections are a distinct risk for bronchiolitis obliterans syndrome and death. Am J Respir Crit Care Med. 2004;170(2):181-7.

15. Kumar D, Erdman D, Keshavjee S, Peret T, Tellier R, Hadjiliadis $\mathrm{D}$, et al. Clinical impact of community-acquired respiratory viruses on bronchiolitis obliterans after lung transplant. Am J Transplant. 2005;5(8):2031-6.

16. Flagg A, Danziger-Isakov L, Foster C, Nasman C, Smedira N, Carl J, et al. Novel $2009 \mathrm{H} 1 \mathrm{~N} 1$ influenza virus infection requiring extracorporeal membrane oxygenation in a pediatric heart transplant recipient. J Heart Lung Transplant. 2010;29 (5):582-4.

17. •• Kumar D, Michaels MG, Morris MI, Green M, Avery RK, Liu $\mathrm{C}$, et al. Outcomes from pandemic influenza A H1N1 infection in recipients of solid-organ transplants: a multicentre cohort study. Lancet Infect Dis. 2010;10(8):521-6. The impact of a pandemic influenza A H1N1 virus on both adult and pediatric solid organ transplant recipients is reported. 
18. Apalsch AM, Green M, Ledesma-Medina J, Nour B, Wald ER. Parainfluenza and influenza virus infections in pediatric organ transplant recipients. Clin Infect Dis. 1995;20(2):394-9.

19. Bridges ND, Spray TL, Collins MH, Bowles NE, Towbin JA. Adenovirus infection in the lung results in graft failure after lung transplantation. J Thorac Cardiovasc Surg. 1998;116(4):617-23.

20. Doan ML, Mallory GB, Kaplan SL, Dishop MK, Schecter MG, McKenzie ED, et al. Treatment of adenovirus pneumonia with cidofovir in pediatric lung transplant recipients. J Heart Lung Transplant. 2007;26(9):883-9.

21. Lujan-Zilbermann J, Benaim E, Tong X, Srivastava DK, Patrick CC, DeVincenzo JP. Respiratory virus infections in pediatric hematopoietic stem cell transplantation. Clin Infect Dis. 2001;33 (7):962-8.

22. - Campbell AP, Chien JW, Kuypers J, Englund JA, Wald A, Guthrie KA, et al. Respiratory virus pneumonia after hematopoietic cell transplantation (HCT): associations between viral load in bronchoalveolar lavage samples, viral RNA detection in serum samples, and clinical outcomes of HCT. J Infect Dis. 2010;201 (9):1404-13. The authors investigate viral loads of RVIs and their impact on outcome in HSCT.

23. Milano F, Campbell AP, Guthrie KA, Kuypers J, Englund JA, Corey L, et al. Human rhinovirus and coronavirus detection among allogeneic hematopoietic stem cell transplantation recipients. Blood. 2010;115(10):2088-94.

24. Small TN, Casson A, Malak SF, Boulad F, Kiehn TE, Stiles J, et al. Respiratory syncytial virus infection following hematopoietic stem cell transplantation. Bone Marrow Transplant. 2002;29(4):321-7.

25. Srinivasan A, Wang C, Yang J, Shenep JL, Leung WH, Hayden RT. Symptomatic parainfluenza virus infections in children undergoing hematopoietic stem cell transplantation. Biol Blood Marrow Transplant. 2011;17(10):1520-7.

26. Verdeguer A, de Heredia CD, Gonzalez M, Martinez AM, Fernandez-Navarro JM, Perez-Hurtado JM, et al. Observational prospective study of viral infections in children undergoing allogeneic hematopoietic cell transplantation: a 3-year GETMON experience. Bone Marrow Transplant. 2011;46(1):119-24.

27. Versluys AB, Rossen JW, van Ewijk B, Schuurman R, Bierings MB, Boelens JJ. Strong association between respiratory viral infection early after hematopoietic stem cell transplantation and the development of life-threatening acute and chronic alloimmune lung syndromes. Biol Blood Marrow Transplant. Jun;16(6):782-91.

28. Cost C, Brock E, Adams-Huet B, Siegel JD, Ardura MI. 2009 pandemic influenza A (H1N1) virus infection in pediatric oncology and hematopoietic stem cell transplantation patients. Pediatr Blood Cancer. 2011;56(1):127-33.

29. Appleton AL, Sviland L, Peiris JS, Taylor CE, Wilkes J, Green MA, et al. Human herpes virus-6 infection in marrow graft recipients: role in pathogenesis of graft-versus-host disease. Newcastle upon Tyne Bone Marrow Transport Group. Bone Marrow Transplant. 1995;16(6):777-82.

30. Kusel MM, de Klerk NH, Holt PG, Kebadze T, Johnston SL, Sly $\mathrm{PD}$. Role of respiratory viruses in acute upper and lower respiratory tract illness in the first year of life: a birth cohort study. Pediatr Infect Dis J. 2006;25(8):680-6.

31. Watzinger F, Suda M, Preuner S, Baumgartinger R, Ebner K, Baskova L, et al. Real-time quantitative PCR assays for detection and monitoring of pathogenic human viruses in immunosuppressed pediatric patients. J Clin Microbiol. 2004;42(11):5189-98.

32. Lee BE, Robinson JL, Khurana V, Pang XL, Preiksaitis JK, Fox JD. Enhanced identification of viral and atypical bacterial pathogens in lower respiratory tract samples with nucleic acid amplification tests. J Med Virol. 2006;78(5):702-10.

33. Sanghavi SK, Bullotta A, Husain S, Rinaldo CR. Clinical evaluation of multiplex real-time PCR panels for rapid detection of respiratory viral infections. J Med Virol. Jan;84(1):162-9.
34. • Kuypers J, Campbell AP, Cent A, Corey L, Boeckh M. Comparison of conventional and molecular detection of respiratory viruses in hematopoietic cell transplant recipients. Transpl Infect Dis. 2009;11(4):298-303. Comparison of testing techniques that showed the value of molecular diagnostics in HSCT.

35. Husain S, Mooney ML, Danziger-Isakov L, Mattner F, Singh N, Avery R, et al. A 2010 working formulation for the standardization of definitions of infections in cardiothoracic transplant recipients. J Heart Lung Transplant. 2011;30(4):361-74.

36. Babady NE, Mead P, Stiles J, Brennan C, Li H, Shuptar S, et al. Comparison of the Luminex xTAG RVP FAST and the Idaho Technology FilmArray RP Assays for the Detection of Respiratory viruses in Pediatric Patients at a Cancer Hospital. J Clin Microbiol. 2012.

37. Lieberman D, Lieberman D, Shimoni A, Keren-Naus A, Steinberg $\mathrm{R}$, Shemer-Avni Y. Identification of respiratory viruses in adults: nasopharyngeal versus oropharyngeal sampling. J Clin Microbiol. 2009;47(11):3439-43.

38. Hammitt LL, Kazungu S, Welch S, Bett A, Onyango CO, Gunson $\mathrm{RN}$, et al. Added value of an oropharyngeal swab in detection of viruses in children hospitalized with lower respiratory tract infection. J Clin Microbiol. 2011;49(6):2318-20.

39. Thavagnanam S, Christie SN, Doherty GM, Coyle PV, Shields MD, Heaney LG. Respiratory viral infection in lower airways of asymptomatic children. Acta Paediatr. 2010;99(3):394-8.

40. Kassis C, Champlin RE, Hachem RY, Hosing C, Tarrand JJ, Perego CA, et al. Detection and control of a nosocomial respiratory syncytial virus outbreak in a stem cell transplantation unit: the role of palivizumab. Biol Blood Marrow Transplant. 2010;16 (9):1265-71.

41. Garcia R, Raad I, Abi-Said D, Bodey G, Champlin R, Tarrand J, et al. Nosocomial respiratory syncytial virus infections: prevention and control in bone marrow transplant patients. Infect Control Hosp Epidemiol. 1997;18(6):412-6.

42. Tablan OC, Anderson LJ, Besser R, Bridges C, Hajjeh R. Guidelines for preventing health-care--associated pneumonia, 2003: recommendations of CDC and the Healthcare Infection Control Practices Advisory Committee. MMWR Recomm Rep. 2004;53 (RR-3):1-36.

43. Sullivan KM, Dykewicz CA, Longworth DL, Boeckh M, Baden LR, Rubin RH, et al. Preventing opportunistic infections after hematopoietic stem cell transplantation: the Centers for Disease Control and Prevention, Infectious Diseases Society of America, and American Society for Blood and Marrow Transplantation Practice Guidelines and beyond. Hematology Am Soc Hematol Educ Program. 2001:392-421.

44. Blanchard SS, Gerrek M, Siegel C, Czinn SJ. Significant morbidity associated with RSV infection in immunosuppressed children following liver transplantation: case report and discussion regarding need of routine prophylaxis. Pediatr Transplant. 2006;10 (7):826-9.

45. Ottolini MG, Curtis SR, Mathews A, Ottolini SR, Prince GA. Palivizumab is highly effective in suppressing respiratory syncytial virus in an immunosuppressed animal model. Bone Marrow Transplant. 2002;29(2):117-20.

46. Romero JR. Palivizumab prophylaxis of respiratory syncytial virus disease from 1998 to 2002: results from four years of palivizumab usage. Pediatr Infect Dis J. 2003;22(2 Suppl):S46-54.

47. Michaels MG, Fonseca-Aten M, Green M, Charsha-May D, Friedman B, Seikaly M, et al. Respiratory syncytial virus prophylaxis: a survey of pediatric solid organ transplant centers. Pediatr Transplant. 2009;13(4):451-6.

48. From the American Academy of Pediatrics. Policy statementsModified recommendations for use of palivizumab for prevention of respiratory syncytial virus infections. Pediatrics. 2009;124 (6):1694-701. 
49. Thomas NJ, Hollenbeak CS, Ceneviva GD, Geskey JM, Young MJ. Palivizumab prophylaxis to prevent respiratory syncytial virus mortality after pediatric bone marrow transplantation: a decision analysis model. J Pediatr Hematol Oncol. 2007;29(4):227-32.

50. de Fontbrune FS, Robin M, Porcher R, Scieux C, de Latour RP, Ferry $\mathrm{C}$, et al. Palivizumab treatment of respiratory syncytial virus infection after allogeneic hematopoietic stem cell transplantation. Clin Infect Dis. 2007;45(8):1019-24.

51. Heikkinen T, Valkonen H, Lehtonen L, Vainionpaa R, Ruuskanen O. Hospital admission of high risk infants for respiratory syncytial virus infection: implications for palivizumab prophylaxis. Arch Dis Child Fetal Neonatal Ed. 2005;90(1):F64-8.

52. Adams R, Christenson J, Petersen F, Beatty P. Pre-emptive use of aerosolized ribavirin in the treatment of asymptomatic pediatric marrow transplant patients testing positive for RSV. Bone Marrow Transplant. 1999;24(6):661-4.

53. Khanna N, Widmer AF, Decker M, Steffen I, Halter J, Heim D, et al. Respiratory syncytial virus infection in patients with hematological diseases: single-center study and review of the literature. Clin Infect Dis. 2008;46(3):402-12.

54. Avetisyan G, Mattsson J, Sparrelid E, Ljungman P. Respiratory syncytial virus infection in recipients of allogeneic stem-cell transplantation: a retrospective study of the incidence, clinical features, and outcome. Transplantation. 2009;88(10):1222-6.

55. Li L, Avery R, Budev M, Mossad S, Danziger-Isakov L. Oral versus inhaled ribavirin therapy for respiratory syncytial virus infection after lung transplantation. J Heart Lung Transplant. 2012;31:839-44.

56. Glanville AR, Scott AI, Morton JM, Aboyoun CL, Plit ML, Carter IW, et al. Intravenous ribavirin is a safe and costeffective treatment for respiratory syncytial virus infection after lung transplantation. J Heart Lung Transplant. 2005;24(12):2114 9.

57. Pelaez A, Lyon GM, Force SD, Ramirez AM, Neujahr DC, Foster $\mathrm{M}$, et al. Efficacy of oral ribavirin in lung transplant patients with respiratory syncytial virus lower respiratory tract infection. J Heart Lung Transplant. 2009;28(1):67-71.

58. Chavez-Bueno S, Mejias A, Merryman RA, Ahmad N, Jafri HS, Ramilo O. Intravenous palivizumab and ribavirin combination for respiratory syncytial virus disease in high-risk pediatric patients. Pediatr Infect Dis J. 2007;26(12):1089-93.

59. DeVincenzo JP, Hirsch RL, Fuentes RJ, Top Jr FH. Respiratory syncytial virus immune globulin treatment of lower respiratory tract infection in pediatric patients undergoing bone marrow transplantation - a compassionate use experience. Bone Marrow Transplant. 2000;25(2):161-5.

60. Sidwell RW, Bailey KW, Wong MH, Barnard DL, Smee DF. In vitro and in vivo influenza virus-inhibitory effects of viramidine. Antiviral Res. 2005;68(1):10-7.

61. Gavin PJ, Katz BZ. Intravenous ribavirin treatment for severe adenovirus disease in immunocompromised children. Pediatrics. 2002;110(1 Pt 1):e9.

62. Howard DS, Phillips IG, Reece DE, Munn RK, Henslee-Downey $\mathrm{J}$, Pittard M, et al. Adenovirus infections in hematopoietic stem cell transplant recipients. Clin Infect Dis. 1999;29(6):1494-501.

63. Muller WJ, Levin MJ, Shin YK, Robinson C, Quinones R, Malcolm J, et al. Clinical and in vitro evaluation of cidofovir for treatment of adenovirus infection in pediatric hematopoietic stem cell transplant recipients. Clin Infect Dis. 2005;41(12):1812-6.

64. Wallot MA, Dohna-Schwake C, Auth M, Nadalin S, Fiedler M, Malago M, et al. Disseminated adenovirus infection with respiratory failure in pediatric liver transplant recipients: impact of intravenous cidofovir and inhaled nitric oxide. Pediatr Transplant. 2006;10(1):121-7.

65. Yusuf U, Hale GA, Carr J, Gu Z, Benaim E, Woodard P, et al. Cidofovir for the treatment of adenoviral infection in pediatric hematopoietic stem cell transplant patients. Transplantation. 2006;81(10):1398-404.

66. Hoffman JA, Shah AJ, Ross LA, Kapoor N. Adenoviral infections and a prospective trial of cidofovir in pediatric hematopoietic stem cell transplantation. Biol Blood Marrow Transplant. 2001;7 (7):388-94.

67. Symeonidis N, Jakubowski A, Pierre-Louis S, Jaffe D, Pamer E, Sepkowitz K, et al. Invasive adenoviral infections in T-celldepleted allogeneic hematopoietic stem cell transplantation: high mortality in the era of cidofovir. Transpl Infect Dis. 2007;9 (2):108-13.

68. Lindemans CA, Leen AM, Boelens JJ. How I treat adenovirus in hematopoietic stem cell transplant recipients. Blood. 2010;116 (25):5476-85.

69. Kumar D, Blumberg EA, Danziger-Isakov L, Kotton CN, Halasa $\mathrm{NB}$, Ison $\mathrm{MG}$, et al. Influenza vaccination in the organ transplant recipient: review and summary recommendations. Am J Transplant. 2011;11(10):2020-30.

70. Madan RP, Tan M, Fernandez-Sesma A, Moran TM, Emre S, Campbell A, et al. A prospective, comparative study of the immune response to inactivated influenza vaccine in pediatric liver transplant recipients and their healthy siblings. Clin Infect Dis. 2008;46(5):712-8

71. Nailescu C, Xu X, Zhou H, Hall H, Wilson AC, Leiser JD, et al. Influenza vaccine after pediatric kidney transplant: a Midwest Pediatric Nephrology Consortium study. Pediatr Nephrol. 2011;26(3):459-67.

72. Hojsak I, Avitzur Y, Mor E, Shamir R, Haimi-Cohen Y, Zakay-Rones $Z$, et al. Antibody response to influenza vaccine in pediatric liver transplant recipients. Pediatr Infect Dis J. 2011;30(6):491-4.

73. Mack DR, Chartrand SA, Ruby EI, Antonson DL, Shaw Jr BW, Heffron TG. Influenza vaccination following liver transplantation in children. Liver Transpl Surg. 1996;2(6):431-7.

74. Danzinger-Isakov L, Kumar D. Guidelines for vaccination of solid organ transplant candidates and recipients. Am J Transplant. 2009;9 Suppl 4:S258-62.

75. Goldschmidt I, Pfister ED, Becker M, Hackl S, Bott OJ, Baumann $\mathrm{U}$, et al. Acceptance and adverse events of the 2009 H1N1 vaccination in immunosuppressed pediatric liver transplant recipients. J Pediatr. 2011;158(2):329-33.

76. Kelen K, Ferenczi D, Jankovics I, Varga M, Molnar MZ, Sallay P, et al. H1N1 vaccination in pediatric renal transplant patients. Transplant Proc. 2011;43(4):1244-6.

77. Gotoh K, Ito Y, Suzuki E, Kaneko K, Kiuchi T, Ando H, et al. Effectiveness and safety of inactivated influenza vaccination in pediatric liver transplant recipients over three influenza seasons. Pediatr Transplant. 2011;15(1):112-6.

78. Esposito S, Meregalli E, Daleno C, Ghio L, Tagliabue C, Valzano A, et al. An open-label, randomized clinical trial assessing immunogenicity, safety and tolerability of pandemic influenza $\mathrm{A} / \mathrm{H} 1 \mathrm{~N} 1$ MF59-adjuvanted vaccine administered sequentially or simultaneously with seasonal virosomal-adjuvanted influenza vaccine to paediatric kidney transplant recipients. Nephrol Dial Transplant. 2011;26(6):2018-24.

79. Haller W, Buttery J, Laurie K, Beyerle K, Hardikar W, Alex G. Immune response to pandemic H1N1 2009 influenza a vaccination in pediatric liver transplant recipients. Liver Transpl. 2011;17 (8):914-20

80. Chik KW, Li CK, Chan PK, Shing MM, Lee V, Tam JS, et al. Oseltamivir prophylaxis during the influenza season in a paediatric cancer centre: prospective observational study. Hong Kong Med J. 2004;10(2):103-6

81. Ison MG, Szakaly P, Shapira MY, Kriván G, Nist A, R. D. Efficacy and safety of oral oseltamivir for influenza prophylaxis in transplant recipients. Antivir Ther. 2012. 
82. Couturier BA, Bender JM, Schwarz MA, Pavia AT, Hanson KE, She RC. Oseltamivir-resistant influenza A 2009 H1N1 virus in immunocompromised patients. Influenza Other Respi Viruses. 2010;4(4):199-204.

83. CDC. Influenza Season Week 35 ending September 5, 2009. 2009 [cited June 11, 2012]; Available from: http:/www.cdc.gov/flu/ weekly/weeklyarchives2008-2009/weekly35.htm2008-2009

84. Coffin SE, Leckerman K, Keren R, Hall M, Localio R, Zaoutis TE. Oseltamivir shortens hospital stays of critically ill children hospitalized with seasonal influenza: a retrospective cohort study. Pediatr Infect Dis J. 2011;30(11):962-6.

85. Dohna-Schwake C, Schweiger B, Felderhoff-Muser U, Fiedler M, Kaiser GM, Paul A, et al. Severe H1N1 infection in a pediatric liver transplant recipient treated with intravenous zanamivir: efficiency and complications. Transplantation. 2010;90(2):223-4.

86. Mancuso CE, Gabay MP, Steinke LM, Vanosdol SJ. Peramivir: an intravenous neuraminidase inhibitor for the treatment of 2009 H1N1 influenza. Ann Pharmacother. 2010;44(7-8):1240-9.

87. Hikita T, Hikita H, Hikita F, Hikita N, Hikita S. Clinical effectiveness of peramivir in comparison with other neuraminidase inhibitors in pediatric influenza patients. Int J Pediatr. 2012;2012:834181.

88. Sugaya N, Kohno S, Ishibashi T, Wajima T, Takahashi T. Efficacy, safety, and pharmacokinetics of intravenous peramivir in children with 2009 pandemic H1N1 influenza A virus infection. Antimicrob Agents Chemother. 2012;56(1):369-77.

89. Ljungman P, de la Camara R, Perez-Bercoff L, Abecasis M, Nieto Campuzano JB, Cannata-Ortiz MJ, et al. Outcome of pandemic
H1N1 infections in hematopoietic stem cell transplant recipients. Haematologica. 2011;96(8):1231-5.

90. Raza K, Ismailjee SB, Crespo M, Studer SM, Sanghavi S, Paterson DL, et al. Successful outcome of human metapneumovirus (hMPV) pneumonia in a lung transplant recipient treated with intravenous ribavirin. J Heart Lung Transplant. 2007;26(8):8624.

91. Weinberg A, Lyu DM, Li S, Marquesen J, Zamora MR. Incidence and morbidity of human metapneumovirus and other communityacquired respiratory viruses in lung transplant recipients. Transpl Infect Dis. 2010;12(4):330-5.

92. Nichols WG, Corey L, Gooley T, Davis C, Boeckh M. Parainfluenza virus infections after hematopoietic stem cell transplantation: risk factors, response to antiviral therapy, and effect on transplant outcome. Blood. 2001;98(3):573-8.

93. Englund JA, Boeckh M, Kuypers J, Nichols WG, Hackman RC, Morrow RA, et al. Brief communication: fatal human metapneumovirus infection in stem-cell transplant recipients. Ann Intern Med. 2006;144(5):344-9.

94. Peck AJ, Englund JA, Kuypers J, Guthrie KA, Corey L, Morrow $\mathrm{R}$, et al. Respiratory virus infection among hematopoietic cell transplant recipients: evidence for asymptomatic parainfluenza virus infection. Blood. 2007;110(5):1681-8.

95. Oliveira R, Machado A, Tateno A, Boas LV, Pannuti C, Machado C. Frequency of human metapneumovirus infection in hematopoietic SCT recipients during 3 consecutive years. Bone Marrow Transplant. 2008;42(4):265-9. 